\title{
The digitalization of universities from a students' perspective
}

\section{Henning Brink ${ }^{1}$, Sven Packmohr ${ }^{2}$, Kristin Vogelsang ${ }^{1}$}

${ }^{1}$ Department of Organization and Information Systems, Osnabrück University, Germany, ${ }^{2}$ Department of Computer Science and Media Technology, Malmö University, Sweden.

\begin{abstract}
The digitalization of higher education institutions is progressing significantly. Though the use of digital assets enhances the students' learning experience and offers new opportunities for administration, there are no uniform standards for the use of digital media in teaching and student services. As educational service providers, universities are dependent on students being able to cope with the structures offered. Thus it is essential to ascertain students' attitudes of the technologies used. We asked students from three blended learning courses about their perceptions. We further asked the students what should be done and by whom. Our results show that students see structural changes occurring not only in themselves but also at the level of the university management. Our research contributes to the actual discussion about the digitalization of higher education by offering suggestions for development from a students' view. The results are valuable for lecturers and faculty managers who want to advance the digitalization of services and learning.
\end{abstract}

Keywords: higher education; organization; digitalization; learning; technology. 


\section{Introduction}

Digitalization is changing our daily lives. As a result of digitalization, teaching and learning at universities are changing in revolutionary ways (Castro, 2019). Amongst other things, knowledge transfer and assessment are digitalized, as are student assistance and administration processes. Digitalization aims to provide enhanced opportunities for constructive learning. Digital structures change access to learning materials, communication, and cooperation between different interest groups. For many universities, digitalization is a trend to follow. Nevertheless, universities are having difficulties adopting technologies (Carver, 2016; Reid, 2014). The various stakeholder groups have very different demands for a digitalized university. These obstacles hinder the digitalization of the universities (Reid, 2014).

This paper contributes to research aiming to solve existing digitalization problems. From the students' point of view, we examine how they perceive the digitalization of the university. We assess their perception by employing dimensions such as trust, learning, and organizational culture. Additionally, we ask students to suggest courses of action and responsibilities. Our research question is two-folded: How do students perceive the current digitalization of universities, and what further possibilities for the development do they suggest?

We have chosen an environment where students experience digitalization as users. They represent a particular (critical) stakeholder group in the universities, especially as they grew up as digital natives (Crittenden, Biel, \& Lovely, 2019). Moreover, digitalization will affect their later professional lives (Friga, Bettis, \& Sullivan, 2003).

In the next section, we present the theoretical foundations of our work and explain the influence of digitalization in higher education. Thereafter, we then introduce the research approach, followed by a presentation of the results. We conclude the paper with short deductions and explain the implications and limitations of our work.

\section{Digitalization of Higher Education Institutions}

Technologies in education motivate lecturers, enrich learning resources, and assist the evaluation of learning goals (Vogelsang, Droit, \& Liere-Netheler, 2019). Further, digitalized processes accelerate service support. When technology merges lecturers with the administration, teaching and student results become more transparent and transferrable. Furthermore, technology has the potential to interweave the universities' competencies of teaching and administration. Because universities operate in a more and more competitive environment, they have to seek efficient processes (Adler \& Harzing, 2017). With the 
ubiquitously digital availability, issues for faculty and administrative staff arise (Proserpio \& Gioia, 2007).

The use and diffusion of digital assets in higher education are very heterogeneous. So far, research has often focused on the evaluation of learning settings. Studies concentrate on the effects of the individual learning success of students (Janson, Söllner, Bitzer, \& Leimeister, 2014) or measure the acceptance of systems (Tselios, Daskalakis, \& Papadopoulou, 2011). Besides drivers and barriers (Gregory \& Lodge, 2015), the studies provide suggestions for the didactic design of blended learning events (Talley \& Scherer, 2013). Only a small branch of research deals with questions of organizational anchoring and adoption (Porter \& Graham, 2016). Problems of organizational integration are often based on resistance to change within institutions (Al-Senaidi, Lin, \& Poirot, 2009). In higher education, research on digitalization is often directly linked to a particular teaching scenario; a generalization of the current results is only possible to a limited extent. There is still a lack of an approach that provides an instrument to address challenges and show solution paths.

\section{Research Method and Sample}

We surveyed during August/September 2019. As a sample, we chose students from digitalized management courses: a) "Business Process Management" (Bachelor in Management/Information Systems) and (b) "Industry 4.0 and Digital Transformation" (Master in Management). The students were invited to fill out a paper-based questionnaire. Additionally, we reached out to students from earlier terms of these courses and the course in "Project Management" (Master in Management/Information Systems) to participate in an online survey. These courses were chosen because they instruct with a high digital component and a supplementary attendance part. In addition, they included progressively digitalized administrative processes such as course subscriptions, exam registrations, and communication supported by technology.

We received 97 completed questionnaires, of which $58.5 \%$ of the respondents were male and $41.5 \%$ female. None indicated a third gender. To examine the influence of gender, we conduct a t-test with a significance rate of 0.92 . The test shows no significant influence of gender on the students' perceptions.

The questionnaire was created based on the existing theory of barriers to digital transformation (Vogelsang, Liere-Netheler, Packmohr, \& Hoppe, 2019) and adjusted to the setting in higher education. We used further existing research to complement the survey questions. The questionnaire included 16 statements related to major fields where problems with digitalization may occur: changed learning, changed services, cultural changes, need for new resources, strategy, and trust. To prevent bias, we did not introduce the statements in the questionnaire to the major fields. We formulated positive and negative questions as a 
means to not influence the students' opinions through choice of words. The students registered their self-reported measures using a five-point Likert-scale, with the scale ranging from "I do not agree at all" (1) to "I do strongly agree" (5). Further, we asked the students to suggest first approaches to overcome these barriers. The last questions were open-text. A pilot test with a focus group of 12 respondents was conducted to uncover comprehension questions and to test the understandability.

\section{Results and Discussion}

The results of the study are presented by showing the means of the statements and standard deviation (std. dev.). Table 1 shows the analysis of the statements about the current situation. The mean values for changed learning show that the students feel no disadvantages from the new learning methods. However, they also do not emphasize a clear progressive continuity in digitally improving the teaching by the university. The students realize digital support and emphasize changed services. Nevertheless, they do not overall highlight a digitalization of service processes. The standard deviation for this statement is relatively high. Students in the digitally transformed courses see a change of the learning culture and emphasize an openness for new teaching concepts. Many of them feel that the learning culture is affected by digitalization. The students agree with the statement that there are new jobs created to handle the digitalization. Nevertheless, the mean value shows that there is still a need for more staff in this field.

Although the students see the university moving forward in terms of digitalization, the majority of them do not think it has a clear digital vision. The mean value for data control is the lowest among the positively formulated questions. At the same time, its standard deviation is the highest. The results show relatively high insecurity about what is happening with the data. In sum, the students are not aware of the increased transparency. The two remaining trust-statements show that the students' transparency does not affect the use of the learning systems. The trust in the university is the highest value of this analysis.

In sum, the students agree there has been an increase in technical support, and they enjoy the advantages of a new learning culture. Our results show that digitalization is equated with modernity and reflected learning conditions. Digitalized teaching concepts are regarded as new and open progressions. Further, the respondents show a high level of trust in the university. Nevertheless, digital service structures can be enhanced. A clear vision is still missing. Furthermore, the staff could trigger the digitalization of services and teaching. 
Table 1. Mean Values and Standard Deviation.

\begin{tabular}{|c|c|c|c|}
\hline Characteristic & Statement & Mean & $\begin{array}{l}\text { Std. } \\
\text { Dev. }\end{array}$ \\
\hline \multirow{3}{*}{$\begin{array}{l}\text { Changed } \\
\text { Learning }\end{array}$} & The changed form of the course harms my learning success. & 1,05 & 1,054 \\
\hline & $\begin{array}{l}\text { I don't see any advantages of the technical support provided } \\
\text { by the digital learning platform in the course. }\end{array}$ & 0,89 & 1,019 \\
\hline & $\begin{array}{l}\text { My university continues using existing methods for teaching } \\
\text { and services. }\end{array}$ & 2,04 & 0,720 \\
\hline \multirow[t]{2}{*}{$\begin{array}{l}\text { Changes } \\
\text { Services }\end{array}$} & $\begin{array}{l}\text { My university offers digital services that support me in my } \\
\text { studies. }\end{array}$ & 3,40 & 1,037 \\
\hline & $\begin{array}{l}\text { I have the impression that the university's internal processes } \\
\text { have been digitized. }\end{array}$ & 2,92 & 1,067 \\
\hline \multirow[t]{3}{*}{$\begin{array}{l}\text { Cultural } \\
\text { Change }\end{array}$} & $\begin{array}{l}\text { The learning culture at the university has not changed due to } \\
\text { digitalization. }\end{array}$ & 2,10 & 1,015 \\
\hline & $\begin{array}{l}\text { The university strives to constantly learn and get better in } \\
\text { how to transform digitally. }\end{array}$ & 3,26 & 0,950 \\
\hline & In my university, there is openness to new ideas in teaching. & 3,36 & 1,012 \\
\hline \multirow[t]{2}{*}{ Resources } & $\begin{array}{l}\text { The university has created specific jobs/projects for the } \\
\text { digitalization. }\end{array}$ & 3,29 & 0,790 \\
\hline & $\begin{array}{l}\text { I have the impression that there are not enough resources } \\
\text { (time, money, IT staff) for the digital learning platform. }\end{array}$ & 2,51 & 1,091 \\
\hline \multirow[t]{3}{*}{ Strategy } & My university is moving forward in terms of digitalization. & 3,33 & 0,943 \\
\hline & $\begin{array}{l}\text { The university management supports the digital } \\
\text { transformation at the university. }\end{array}$ & 3,25 & 0,830 \\
\hline & In my university, we have a clear vision or DT strategy. & 2,94 & 0,839 \\
\hline \multirow[t]{3}{*}{ Trust } & $\begin{array}{l}\text { I have the impression that I control the data that is stored } \\
\text { about me. }\end{array}$ & 2,55 & 1,155 \\
\hline & $\begin{array}{l}\text { I trust the university in handling the data I generate when } \\
\text { using the platform. }\end{array}$ & 3,86 & 0,989 \\
\hline & $\begin{array}{l}\text { The transparency of the data (to which the lecturer has } \\
\text { access) does not affect my use of the digital learning } \\
\text { platform. }\end{array}$ & 3,66 & 1,019 \\
\hline
\end{tabular}


After the analysis of the statistical values, we will discuss first development-paths suggested by the students. The proposed solutions are each addressed to a specific stakeholder group, the universities' management, the administration, the lectures, and the students themselves.

The university management plays a crucial role in defining a digitalization strategy. Institutional support, openness to innovation, and change (Reid, 2014) are essential. The management should actively support projects and lecturers who promote digitalization. Students request guidelines that regulate the use of digital media in university teaching and demand that the university encourages lecturers to transform teaching. As a support, the universities should provide funds to create new positions for digital experts.

On the administration level, many students see a necessary condition for the digitalization of services and teaching in a further and faster development of adequate learning management systems. In particular, the aspects of interactivity, integration of chat-based forums, the possibility to access all content without a permanent internet connection, and the compatibility with all end devices were emphasized. Students also request more computer rooms to be independent of their private technical equipment.

In order to fully benefit from all technical possibilities not only the pure provision of online systems is of importance. The lack of institutional support (Porter \& Graham, 2016) has to be overcome. Students report that lecturers are currently not exploiting the full potential. To overcome these barriers, universities are required to create service centers that help lectures to digitize courses into blended learning scenarios.

In the literature, there is an additional aspect of alliances that can help to overcome organizational barriers (Ngwenyama \& Nielsen, 2014). Well-trained technical support staff should be available to learners and lectures. As a consequence, teachers can concentrate on the content rather than focus on the medium. A good exchange will lead to well-trained staff with a clear focus on media competence and content creation in the long term, which will increase media richness at universities.

The surveyed students demand that there is a greater sense of willingness amongst the lectures to change to digitalized courses and seminars. However, digitalization requires a considerable additional effort that may overstrain the capacity of the lecturers in terms of time and competence. Even if lecturers are willing to try more digitalized forms of instruction, a lack of knowledge and considerable uncertainty about how digital media can be effectively integrated into courses can add to their ambivalence. As a response, students see a bundling of resources as necessary. Digital structures should be linked across departments or even across universities. The above-mentioned service centers can help to stop the silo mentality. 
Students welcome the digitalization of teaching and the increased availability of online content. However, they fear the loss of social contact when face-to-face classes are removed. Students are aware of the required increased self-discipline when lectures and exercises are available online and when attendance is no longer mandatory. To address this, they seek further expansion of blended learning concepts. In their view, blended learning should offer a space for creative exchange combined with the advantages of digitalized content. Interaction with lecturers and fellow students in face-to-face classes should not fall short.

For the future, the students desire an expansion of blended learning concepts, online platforms, and administrative processes, which they see as the most promising forms of and uses for digitalization in higher education.

\section{Limitations and Further Research}

This study concerns students' perception of the digitalization of higher education institutions. We tested our model among a group of management students in different courses with a blended design.

Our results are suitable for lecturers and faculty managers. We aim at those who want to build a blended learning environment and who want to promote the digitalization of services and learning. The lack of a clear vision for digitalization is a problem that is perceived down to the student level. Often, there is a lack of support from university management. The use of blended learning courses ensures that the university is regarded as modern and open to new ideas. Universities can promote blended learning concepts and thus advance their digitalization image. Such change requires training for students, for lecturers, and for administrative support, all of whom can significantly influence digitalization.

Digitalization enables new teaching methods with a focus on higher levels of interaction. The online availability of content does not necessarily mean that students will stay away from the courses. Rather, it is a chance to use the time spent in class more effectively to reach higher levels of knowledge transfer. Though students still seek direct exchange with lecturers, they demand higher added value. The lecturer's role changes to that of a learning coach in face-to-face settings as students prepare themselves with online content.

Our research is also not entirely free of limitations. The study was conducted with a sample from management studies, that is, a group of students who are positively biased towards digitalization. Therefore, it would be interesting to compare the findings not only with a different subject culture but also with students without a blended learning experience. 


\section{References}

Adler, N. J., \& Harzing, A.-W. (2017). When Knowledge Wins: Transcending the Sense and Nonsense of Academic Rankings. Academy of Management Learning \& Education, $8,72-95$.

Al-Senaidi, S., Lin, L., \& Poirot, J. (2009). Barriers to adopting technology for teaching and learning in Oman. Computers \& Education, 53, 575-590.

Carver, L. B. (2016). Teacher Perception of Barriers and Benefits in K-12 Technology Usage. Turkish Online Journal of Educational Technology - TOJET, 15, 110-116.

Castro, R. (2019). Blended learning in higher education: Trends and capabilities. Education and Information Technologies, 24, 2523-2546.

Crittenden, W. F., Biel, I. K., \& Lovely, W. A. (2019). Embracing Digitalization: Student Learning and New Technologies. Journal of Marketing Education, 41, 5-14.

Friga, P. N., Bettis, R. A., \& Sullivan, R. S. (2003). Changes in Graduate Management Education and New Business School Strategies for the 21st Century. Academy of Management Learning \& Education, 2, 233-249.

Gregory, M. S.-J., \& Lodge, J. M. (2015). Academic workload: The silent barrier to the implementation of technology-enhanced learning strategies in higher education. Distance Education, 36, 210-230.

Janson, A., Söllner, M., Bitzer, P., \& Leimeister, J. M. (2014). Examining the effect of different measurements of learning success in technology-mediated learning research. 35th International Conference on Information Systems (ICIS), 1-10.

Ngwenyama, O., \& Nielsen, P. A. (2014). Using organizational influence processes to overcome IS implementation barriers: Lessons from a longitudinal case study of SPI implementation. European Journal of Information Systems, 23, 205-222.

Porter, W. W., \& Graham, C. R. (2016). Institutional drivers and barriers to faculty adoption of blended learning in higher education: Drivers and barriers to blended learning adoption. British Journal of Educational Technology, 47, 748-762.

Proserpio, L., \& Gioia, D. A. (2007). Teaching the Virtual Generation. Academy of Management Learning \& Education, 6, 69-80.

Reid, P. (2014). Categories for barriers to adoption of instructional technologies. Education and Information Technologies, 19, 383-407.

Talley, C. P., \& Scherer, S. (2013). The Enhanced Flipped Classroom: Increasing Academic Performance with Student-recorded Lectures and Practice Testing in a “Flipped” STEM Course. Journal of Negro Education, 82, 339-347, 357.

Tselios, N. K., Daskalakis, S., \& Papadopoulou, M. (2011). Assessing the Acceptance of a Blended Learning University Course. Educational Technology \& Society, 14, 224-235.

Vogelsang, K., Droit, A., \& Liere-Netheler, K. (2019). Designing a Flipped Classroom Course-a Process Model. Proceedings of the 14th International Conference on Wirtschaftsinformatik, 345-359.

Vogelsang, K., Liere-Netheler, K., Packmohr, S., \& Hoppe, U. (2019). Barriers to Digital Transformation in Manufacturing: Development of a Research Agenda. Proceedings of the 52st Hawaii International Conference on System Sciences, 4937-4946. 